\title{
Selling Out: The Inauthenticity Discount in the Craft Beer Industry
}

\author{
Justin Frake \\ Robert H. Smith School of Business, University of Maryland, College Park, MD 20742, justin.frake@rhsmith.umd.edu
}

This paper investigates why audiences devalue organizations that behave inauthentically. One explanation is that inauthenticity leads to lower perceptions of product quality. This stems from the audience's doubt of an inauthentic actor's capability and commitment to produce high-quality goods. Another explanation is that audiences discount the symbolic value - or what the object represents - of products from inauthentic organizations. I empirically test each of these mechanisms in the craft beer industry. First, I exploit exogenous variation in consumers' knowledge of craft brewers' inauthentic identity (whether they are owned by a corporate brewer) to empirically demonstrate an inauthenticity discount. Next, I decompose audience evaluations to show that knowledge of a producer's inauthenticity does not have a statistically significant impact on evaluators' sensory experience of the product - its taste, smell, appearance, or mouth-feel - but that it does affect audience evaluations of the product's symbolic value.

Key words: inauthenticity discount, authenticity, symbolic goods, evaluations, on-line reviews, cultural goods, mergers, acquisitions 


\section{Introduction}

In 2011, Anheuser-Busch InBev (AB-InBev) acquired Goose Island Brewery, one of the most respected craft brewers in the world. The goal of the acquisition was to allow Goose Island to grow and to facilitate AB-InBev's entry into the lucrative top-end of the craft beer segment. But the acquisition had many detractors. Some believed that Goose Island ales would become "watered down" like AB-InBev's other products (e.g. Bud Light). This sentiment was reflected in the comments of one onlooker who said "My concern is that some accountant at InBev will come up with... clever ways to make more money [by] substituting ingredients or making the brewing process less expensive" (Esterl and Mickle 2014). AB-InBev did their best to quell these concerns. For example, Goose Island's Brand Ambassador retorted "the beers will not change." Others worried that consumers may perceive a change in quality even if the products remained the same because consumers often use the identity of the producer to make quality inferences. For example, one commenter said, "maybe its me but the recent Goose Island beer I drank tasted just like Bud" (Esterl and Mickle 2014). Still others worried that consumers may feel betrayed because Goose Island had "sold-out" and no longer represented small, local, authentic production.

To determine why audiences desire products from authentic organizations I build on a growing body of literature that recognizes value as socially constructed (Kovács and Sharkey 2014, Simcoe and Waguespack 2011, Malter 2014, Leung and Sharkey 2014, Negro and Leung 2013, Pontikes et al. 2010, Pontikes 2012). More recently, scholars have demonstrated the importance of organizational authenticity as one important characteristic in determining audience perceptions of value (Kovács et al. 2013, Hahl 2015, Beverland 2005, Carroll and Wheaton 2009, Lehman et al. 2014, Verhaal and Khessina 2015). These studies have identified authenticity as an important phenomena in a number of settings including sports (Hahl 2015), music (Peterson 1997, Grazian 2005), art (Fine 2003, Hahl et al. 2015, Kim 2016), wine (Beverland 2005, Negro et al. 2007), whiskey (McKendrick and Hannan 2014), and dining (Kovács et al. 2013, Lehman et al. 2014).

Few studies, however, have demonstrated a convincing causal connection between authenticity and organizational outcomes ${ }^{1}$. One difficulty in identifying a relationship between authenticity and audience evaluations, in particular, is that inauthentic behavior may impact audience evaluations through a variety of mechanisms. First, acts of inauthenticity may have an objective impact on product quality. For instance, independent artists that sign with corporate record labels (an act of inauthenticity) may later release albums that sound different than they otherwise would have if they remained independent. Therefore, it is critical that any empirical investigations of the effect of inauthentic acts of audience perceptions control for objective product quality.

\footnotetext{
${ }^{1}$ See Kovács et al. (2013) for a notable exception.
} 
Besides the empirical challenge of identifying the effects of authenticity, the theoretical mechanisms that explain why audiences value authenticity are difficult to tease apart. One mechanism suggests that when audiences are unable to perfectly assess product quality they will rely on other observable characteristics, like acts of (in)authenticity, to make quality inferences. For example, Carroll and Wheaton (2009, p. 257) suggests that even though acts of authenticity "may or may not technically be related to quality... they often are perceived as such." Similarly, Kovács et al. (2013, p. 459) suggest that consumers "may use authenticity as a subtle or sophisticated way to convey quality judgments." Therefore, audiences may mistakenly evaluate products from inauthentic organizations as lower quality even when they are not. Another explanation is that audiences value authentic products for their symbolic value, or what they represent (Bourdieu 1985). Symbolic goods are distinct from the physical object and often allow audiences to demonstrate their social standing or personal characteristics. For example, connoisseurs of "underground," or obscure, music may use this knowledge to demonstrate their social superiority over fans of more popular music. Symbolic goods also allow audiences to enact their deeply held moral or ethical beliefs. For instance, if consumers believe that "buying local" is more ethical then they may derive utility from buying an identical product from a local producer over a national chain. In either case, the reason the audience member values a good more is separate from the object's physical manifestation.

I contribute to the growing literature on organizational authenticity in several ways. First, I provide the first causal evidence, outside of a laboratory setting, that organizational authenticity affects audience evaluations. Next, I offer the first study to investigate the consequences of inauthentic behavior by organizations previously considered authentic. Finally, this study is the first to empirically demonstrate that acts of inauthenticity affect the symbolic value attributed to the inauthentic organization's products, independent of product quality or perceptions thereof. Empirically, I exploit an arbitrary website design decision that makes a treatment group aware of a craft brewer's inauthentic identity. I then show that knowledge of a producer's inauthenticity does not significantly affect quality ratings but that it does negatively affect perceptions of symbolic value.

\section{Organizational Authenticity and Audience Evaluations}

Authenticity is socially constructed (Peterson 2005, Carroll and Wheaton 2009, Baugh 1988) within objective constraints (Zuckerman 2012). Although scholars have defined several different types of authenticity (type, moral, idiosyncratic, etc.), I adopt the general meaning of the term which describe whether an actor is considered genuine and acts in accordance with their true character (Trilling 1972, Carroll and Wheaton 2009). Importantly, authenticity is conferred on an actor by an external audience. Therefore, audiences must first infer a focal actor's character by observing 
identity claims, category membership and past behavior. From these observations, audiences establish expectations about how the actor should behave to remain authentic. An actor is considered authentic if they act in accordance with these expectations.

Prior studies have linked authenticity to perceptions of value, or the total utility a consumer derives from a good or service. For example, Kovács et al. (2013) find that restaurant-goers assign higher ratings to establishments they perceive to be more authentic. Zuckerman and Kim (2003) show that demand for a movie is impacted by whether it is perceived as being targeted at massmarket (inauthentic) or art-house (authentic) audiences. Finally, Carroll and Swaminathan (2000) suggest, but do not empirically demonstrate, that consumers devalue beers produced by corporate brewers because they are perceived as inauthentic.

Extant research has not fully explained why inauthenticity leads to lower perceptions of value. Perceptions of value are critical for organizational success and survival. Evaluations are, however, complex, subjective and multifaceted. One reason for this is that consumption and evaluation are, fundamentally, social acts. A simplistic view of audience evaluations (e.g. product ratings) assumes that they are merely an evaluation of product quality. However, scholars have long recognized the complexity of consumer evaluations and ratings. For example, marketing scholars distinguish between the functional and symbolic aspects of a product (Hirschman and Holbrook 1982, Grubb and Grathwohl 1967, Gardner and Levy 1955). Levy (1959, p. 118), notes that "People buy products not only for what they can do, but also for what they mean." When thought of in this way, the total utility an audience member derives from an object can be broken down into two component parts: the physical aspects of the object and the non-physical or symbolic value of the object (Bourdieu 1985). The first component I will refer to as the consumer's "perception of quality" and the latter I will refer to as a "symbolic value." In the following sections, I explore why authenticity may independently affect perceptions of quality and symbolic value.

\subsection{Authenticity's Effect on Perceptions of Quality}

In cases where quality is imperfectly observable ${ }^{2}$, audiences rely on more easily observable characteristics to make quality inferences (Negro and Leung 2013, Zuckerman et al. 2003, Spence 1973). For example, Negro and Leung (2013) find that knowledge of a wine producer's boundary-spanning identity affects product ratings. Similarly, authentic production is generally correlated with quality. For example, authentic restaurants tend receive higher ratings (Kovács et al. 2013). Furthermore, Beverland (2005) found that authenticity and commitment to quality were highly correlated in the wine industry. In these cases, audiences may use an organization's (in)authentic identity to make

${ }^{2}$ Craft beer is one of these cases. Carroll and Swaminathan note that "like many specialty products, malt beverages are inherently difficult to categorize and evaluate because of their subtle and ambiguous complexities" (2000, pg. $730)$. 
product-quality inferences $^{3}$. In other words, audiences may make probabilistic judgments about a product's quality based on previously observed correlations between authenticity and quality. For example, craft brewers are known for producing higher quality products than are large corporate brewers ${ }^{4}$. Therefore, ceteris peribus, consumers may infer that a product is lower quality when they are aware that it is produced by an inauthentic producer.

Audiences may also question an inauthentic organization's ability to to produce high-quality products. Inauthentic organizations are often perceived as such because they seek mass-audience appeal. For example, chain restaurants are perceived as inauthentic because they foster "a standardized lifestyle and culture in conflict with the expression of distinctive - that is, authentic - social identities" (Kovács et al. 2013, p. 462). However, prior research has demonstrated that appealing to the masses comes at the cost of appealing less to connoisseurs, or those audience members with the most distinctive and discerning tastes (Rossman and Schilke 2014, Zuckerman and Kim 2003). For instance, Zuckerman and Kim (2003) find that, in the market for films, there is a trade-off between mass-appeal and "art house" appeal. They argue that it is difficult to simultaneously appeal to the different tastes of the mass-market and connoisseurs because of their disparate preferences and expectations. Therefore, connoisseurs may interpret an organization's inauthentic identity as a sign that the organizations products will not match their particular tastes ${ }^{5}$. Iain Lowe, spokesman for the Campaign for Real Ale, reflected this sentiment in an article titled "The Plot to Destroy America's Beer" (Leonard 2012). He said, "You often see when a local brand is taken over by a global brewer, the production is raised a lot. If you're trying to produce a lot of beer, you don't want a beer that some people may object to the taste of it, so you may actually make the taste a little blander."

Finally, audiences may doubt an inauthentic organization's commitment and dedication to producing high-quality products. Actors seen as being extrinsically motivated (by fame, fortune, etc.) are considered less authentic than those seen as intrinsically motivated. For example, Hahl (2015) argues that when audiences believe actors are motivated by monetary rewards, they doubt the actor's authenticity. Therefore, if audiences question inauthentic organizations' motivation for acting in a given market, they may also suspect them of compromising product quality, or "cutting corners," in an effort to maximize profits. This sentiment is reflected by one commenter who said,

\footnotetext{
${ }^{3}$ Audiences perceive a good's quality both before and after experiencing it. It is important to note that identity likely has different (and perhaps stronger) ex ante effects on perceptions of quality. In my empirical setting, evaluations are presumably made ex post so I am not able to empirically investigate these differences.

${ }^{4}$ Products from corporate brewers have an average rating of 42 while craft brewers have an average rating of 73 percent (based on ratings from ratebeer.com). Furthermore, corporate brewers are known for using lower-cost "adjuncts" like corn and rice rather than malted barley.

${ }^{5}$ The users in my empirical setting represent primarily connoisseurs.
} 
in reaction to news that a craft brewer had been purchased by AB-InBev, "My concern is that some accountant at InBev will come up with... clever ways to make more money [by] substituting ingredients or making the brewing process less expensive" (Esterl and Mickle 2014). In contrast, authentic organizations are seen as intrinsically motivated by their sincere dedication to the craft or social movement. Therefore, audiences may believe that authentic organizations are less likely to compromise on quality, even if doing so may benifit their bottom line. This idea is reflected in the comments of James Watt, founder of the craft brewery BrewDog, in an interview with The Guardian (Ruddick 2015). He first identifies corporate brewers as being externally motivated by profits, saying, "We set ourselves apart from [corporate breweries], as they are focused heavily on making money." Next, he highlights the intrinsic motivation behind his craft brewery: "We just wanted to make the beers we wanted to drink." Finally, Watt argues that because of this intrinsic motivation, "We don't compromise... We don't cut corners, we don't use additives, or filter or pasteurize the beer, as these things all affect its flavor... [unlike] the pedestrian beers peddled by multinational conglomerates." Therefore, inauthenticity may be interpreted by audiences that an organization lacks the capability or commitment to produce high-quality products.

In summary, inauthenticity may cause evaluators to perceive a good as lower quality because 1) there is a generally perceived association between inauthenticity and low-quality production, (2) they question the producers ability to produce high quality goods, (3) they doubt the producer's capability and commitment to producing high quality goods. Therefore, I predict:

Hypothesis 1: Audiences will perceive goods from inauthentic producers to be lower quality, controlling for actual product quality.

\subsection{Authenticity's Effect on Evaluations of Symbolic Value}

The utility derived from an object may not come from the object's physical attributes alone. For example, a parent may value a painting made by their child, not because of the inherent quality of the artistic work, but because of what the painting represents. In this view, goods consist of two parts: the physical object and the symbolic object (Bourdieu 1985). A physical object is all of the physical, or sensory, characteristics of the object. A symbolic object is what the good represents. Therefore, a good may have symbolic value even if it lacks any physical usefulness.

The value of a symbolic good may be intrinsically or extrinsically derived. Extrinsically motivated symbolic goods are valuable for the social advantage they afford. For example, status symbols are one well-studied symbolic good. Consumers may buy an expensive luxury car, not just for the car's physical attributes, but also because it demonstrates wealth and status. Veblen (1899) observed that consumers engage in "conspicuous consumption," where they purchase conspicuous goods like luxury cars, private jets, lavish estates and expensive wines to signal wealth and status. These 
goods, however, are ineffective in portraying other socially valued characteristics like morality, conscientiousness, and intelligence because these attributes are often uncorrelated with wealth (Leibenstein 1950). Recent studies have begun to explore how consumers use symbolic goods to portray non-status related attributes. For example, Sexton and Sexton (2014) found evidence of "conspicuous conservation," whereby consumers use displays of conservation and other prosocial behaviors to demonstrate conscientiousness. They find that consumers' willingness to pay for conspicuous green products increases with the environmental preferences of their peers. Others have found that acts of charitable giving are used to express altruism (Gneezy and Rustichini 2000, Glazer and Konrad 1996). Similarly, products from authentic organizations can be used to express the values, knowledge, taste, and sophistication of the consumer (Bourdieu 1985). For example, Bulik (2009) says that "[y] our choice of beer can be as telling about your personality as what kind of clothing you wear or the car that you drive."

Consumption of authentic products may express the consumer's individuality. Leibenstein (1950) describes the "snob effect" as a case in which individual demand for a good is inversely related to the aggregate demand for the good. Mason (1981, p. 128) explains that the snob effect is present when audiences "come to reject a particular product as and when it is seen to be consumed by the general mass of people." Therefore, "snobs" may value authentic items, not because they are higher quality, but to distinguish themselves from the "unsophisticated masses." Therefore, once an organization is seen as inauthentic, its products are no longer effective in communicating the consumer's distinctiveness and sophistication to others.

Symbolic value may also be intrinsically derived. There are two primary reasons audience members may intrinsically value authentic goods. The first relates to Grubb and Grathwohl's (1967) self-enhancement theory, which argues that symbolic goods may be intrinsically valued because they enhance the self-concept of the consumer. Self-concept is the "totality of the individual's thoughts and feelings having reference to himself as an object" (Rosenberg 1979, pg. 7). In this model, people have an image of themselves, which they consider valuable. Therefore, they are willing to allocate scarce resources in an effort to protect and enhance their self-image. In particular, Grubb and Grathwohl (1967) predict that "the consuming behavior of an individual will be directed toward the furthering and enhancing of his self-concept through the consumption of goods as symbols." Sirgy (1982, pg. 531) argues, for instance, that purchasing goods seen as high status will reinforce the consumer's image of himself as high status. Authentic goods may be consumed in similar ways. People who see themselves as authentic, or who would like to see themselves as authentic, may use goods from authentic producers to enhance their self-image.

Relatedly, authentic goods allow consumers to enact their deeply-held moral and ethical positions. This reason may be especially salient in markets defined by oppositional identities or that 
are morally contested. These markets create moral and ethical boundaries between categories, and crossing them may be seen as betrayal (Phillips et al. 2013). For example, the beer industry is one well-know market where oppositional identities exist. This because the craft beer movement grew in reaction to the significant consolidation, corporatization, and homogenization of the beer industry through most of the twentieth century (Carroll and Swaminathan 2000). To many in the craft beer movement, corporate brewers are seen as "the enemy" (Lewis 2014, p. 196) or "the devil" (Schneider 2012). Oppositional identities also exist in other markets where authenticity is particularly salient such as whiskey (McKendrick and Hannan 2014), wine (Negro et al. 2011), and cuisine (Rao et al. 2005). In these markets, consumers may view supporting inauthentic producers as immoral or as a betrayal to the social movement that they identity with. For instance, when Goose Island was purchased by AB-InBev, the Chicagoist reported that "[c]ries of 'sell-out' shrieked across Facebook and Twitter. Critics made overblown comparisons between [Anheuser Busch] and Hitler" (Schneider 2012). A member of BeerAdvocate, a beer rating website, said "I never buy Inbev and I tell my friends... why they shouldn't. I don't care if that makes me a snob, AB-Inbev is evil and I won't give them a dime." Hence, in the face of inauthenticity some consumers will seek products from authentic organizations and reject products from inauthentic organizations on moral grounds.

In summary, audiences may discount the symbolic value of a good from an inauthentic producer because (1) they believe the good to be less effective in demonstrating superior taste, knowledge, and sophistication to others; (2) the good no longer enhances the authentic self-concept of the consumer; and (3) consuming products from inauthentic producers is seen as morally suspect. Therefore, I predict:

Hypothesis 2: Audiences will perceive goods from inauthentic producers to have lower symbolic value, independent of actual or perceived product quality.

\section{Empirical Context and Sample \\ 3.1. Context and Design}

I test my theoretical propositions in the craft beer industry, where Carroll and Swaminathan (2000) pose authenticity as a defining characteristic. Craft brewers use "public claims about tradition and authentic craft-style production" (p. 733) to collectively differentiate themselves from corporate brewers. Leonard (2015) echoed this sentiment, saying that craft brewers "have built a thriving niche... [by] positioning themselves as the underdogs in a war with large corporations, most notably AB InBev." For some time, craft brewers seemed to be winning the war by effectively excluding corporate brewers from entering the craft beer industry. Carroll and Swaminathan (2000) document the pre-2000 failure of corporate brewers to successfully introduce products that appealed to craft 
beer drinkers. They attributed the failure of the corporate brewers to a lack of authentic identity. Since 2000, however, corporate brewers have changed strategy. Rather than focus on creating their own craft products, corporate brewers have begun to acquire craft brewers in an attempt to purchase their authentic identities. In the example described above, Anheuser-Busch InBev purchased Goose Island, one of the most prestigious craft brewers in the world. When asked why they made the purchase, one Anheuser-Busch executive explained, "We bought Goose Island for what Goose Island was: authentic, very credible" (Schultz 2013).

But some audience members have reacted negatively to news of acquisitions of craft brewers. Graham Mackay, former executive chairman of SABMiller, said that some in the craft movement see corporate brewers as "the enemy" Lewis (2014, p. 196). He went on to say that they "think we're stealing their authenticity." In what follows, I empirically investigate how and why audiences react negatively to inauthenticity. Specifically, I test audience perceptions of the beer's quality and its symbolic value when they are made aware that a craft brewer is owned by a large, corporate brewer.

My null hypothesis is that authenticity does not directly affect audience evaluations in the craft beer market. This may hold if product quality - or the sensory experience that the physical object delivers - is the essential criteria by which consumers judge craft beers. Supposing that quality is the exclusive concern of consumers, we may still expect a correlation between authenticity and audience evaluations. One reason is that authentic craft brewers generally produce higher quality products than inauthentic corporate brewers ${ }^{6}$. If a beer's quality is not perfectly observable to the consumer then they may use the commonly perceived association between authenticity and quality to make quality inferences.

Kovács et al. (2013) provide some of the first empirical tests of organizational authenticity on audience evaluations. Importantly, they acknowledge the potential of unobserved quality to confound their results. They employ content analysis of on-line restaurant reviews to measure authenticity. To control for quality, they use content analysis of quality related words and thirdparty (Zagat) reviews. This cross-sectional analysis represents one of very few studies to show that perceived authenticity affects audience evaluations. They also provide evidence that ownership structures are correlated with perceived authenticity. The authors supplement this analysis with an experimental study using Amazon's Mechanical Turk. Kovács et al. (2013) demonstrate experimentally that authenticity is causally related to audience evaluations.

I take advantage of a quasi-experiment to examine the causal effect of inauthenticity in the field. Specifically, I use the acquisitions of craft brewers by large corporate brewers as a negative

${ }^{6}$ None of Anheuser-Busch InBev's products have an average rating over 47 (out of 100), which is well below the average rating of 69 (Calculated by the author using ratings data from Ratebeer.com). 
shock to the authenticity of the craft brewer. However, for ownership structure to affect audience perceptions of authenticity, audience members must be aware of the craft brewer's true ownership. I use exogenous variation in consumers' knowledge of a craft brewer's ownership to identify the effects of perceptions of authenticity on audience evaluations of quality and symbolic value. Specifically, I exploit an arbitrary design difference between the two similar beer ratings websites. One website, ratebeer.com, displays the corporate owner's identity on product ratings pages, while the other, beeradvocate.com, does not. Therefore, I exploit this exogenous variation in the knowledge that a consumer has of the craft brewers' corporate ownership to identify the effect of inauthenticity on audience evaluations $^{7}$. Figure 1 demonstrates the product page of Matilda, a Goose Island product, on ratebeer.com (treatment site) after acquisition by Anheuser-Busch InBev. The treatment site displays the name of the acquirer ("AB-InBev" for Anheuser-Busch InBev). Before acquisition, the product page was identical except "(AB-InBev)" was not included in the brewery's name. This design feature makes all visitors of the treatment website aware of the craft brewer's corporate ownership. In contrast, the control group's product pages are not impacted by craft brewer's acquisition. This arbitrary design difference acts as my identification strategy.

\section{Goose Island Matilda Brewed by Goose Island Beer Company (AB-InBev) Chicago, Illinois USA \\ Style: Belgian Ale | Ratings: 1841 | Alcohol: 7\%}

Figure 1 Screen print of Goose Island Matilda on Ratebber.com after acquisition by AB-InBev.

\subsection{Data and Sample}

To test my hypotheses concerning the effects of authenticity on audience evaluations, I collected data from two similar beer rating websites: ratebeer.com and beeradvocate.com ${ }^{8}$. These websites are the most influential and comprehensive sources of beer ratings data available. These sites were founded in 2000 and 1998, respectively. They allow users to create individual profiles and record tasting notes, ratings, and reviews. They contain millions of reviews and tens of thousands of products. One advantage that these sites have is that audiences use them to record their own preferences so that they can later recall which products they most like. The fact that raters later rely on their earlier evaluations provides strong incentives to give unbiased evaluations.

${ }^{7}$ I use instances of "selling out," or craft brewers being acquired by corporate brewers, in my empirical analysis. However, I am not able to determine whether the effects I find are due to perceptions of "selling out" (moving from independently-owned to corporate-owned) or of corporate ownership alone. As one anonymous reviewer pointed out, consumers would need more information to determine whether a corporately-owned firm had ever been independent.

${ }^{8}$ Special thanks to Julian McAuley for generously sharing these data (McAuley et al. 2012). 
I limit my sample to only those craft brewers that were acquired by a large corporate brewer from 2000 to 2013 and that were documented on the ratebeer.com product page of the craft brewer (see Figure 1 for an example). I exclude products with less than 25 product ratings during the period (to exclude limited release products and experimental beers). I produced common firm and product identifiers across the two sources to allow for the inclusion of fixed-effects. My final sample consists of five acquisitions. Three are by Anheuser Bush-Invebev (Goose Island in 2011, Oland Brewery in 2009 and Brauerei Beck in 2001), one by Labatt-InBev (Lakeport Brewing Company

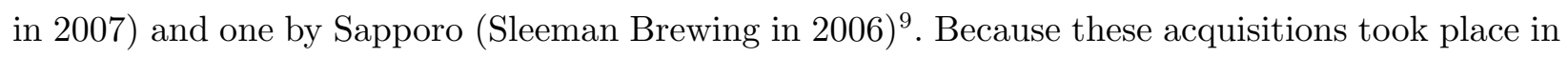
substantially different time periods, there is little chance that unobserved variables (for example, an unobserved change to one of the websites) are responsible for the results. I only include reviews that were made one year before or after the acquisition occurred. I have chosen this time frame to provide sufficient statistical power, while reducing the chance of including other treatments and of treatment contamination (users of the control group becoming aware of the acquisitions through outside sources $)^{10}$. My final sample contains five acquisitions and 13,398 reviews within one year of the acquisition. The review will be my unit of analysis. Figure 2 compares the monthly review volumes for the treatment and control groups around the time of treatment. The figure demonstrates that the ratings volumes of the two sites are similar and that monthly volumes fluctuate in tandem.

\subsection{Empirical Design}

Acquisitions are associated with a number of supply-side effects. For example, acquisitions may affect the production process, distribution footprint, advertising expenditure, internal incentive structure, and personnel composition of the acquired craft brewers. Simply comparing pre- and post-acquisition means would confound these supply-side effects with the demand-side (audience) effects hypothesized above. To the extent that supply-side effects exist, I econometrically account for them by using a difference-in-differences (DD) design (Angrist and Pischke 2008). My identification strategy depends on comparing the ratings of those who were made aware of the craft brewers' corporate ownership with the ratings of those who were not. With the assumption that supply-side effects impact both websites equally, the difference-in-difference design will control for changing recipes, production methods, distribution, product freshness, or any other "actual" changes to product quality after the acquisition takes place.

\footnotetext{
${ }^{9}$ During my sample period, there were several other 'borderline' cases of inauthenticity that I have excluded from analysis because they are not clearly considered acts of inauthenticity. For example, Creemore Springs is a large Canadian brewery specializing in lagers that was purchased by MillerCoors. Because they were previously large and produced lagers, which are associated with corporate brewers, this is not clearly and act of inauthenticity. My results are robust to the inclusion of these 'borderline' cases.

${ }^{10}$ Results are robust to nine--month and two-year windows.
} 


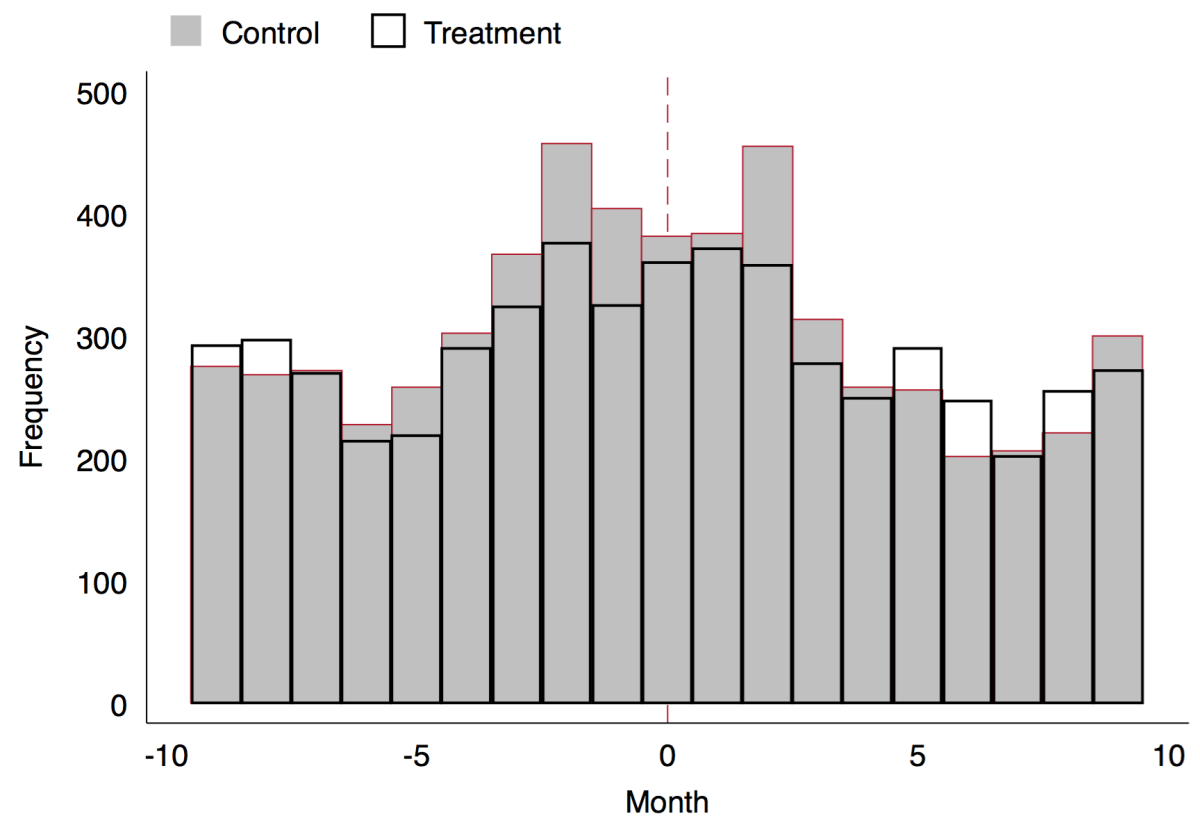

Figure 2 Comparison of pre- and post-treatment ratings volumes

It is important to note that it is possible, and likely, that there are a portion of users in the control group that are also aware of the craft brewers' acquisition. This means that some members of the control group may also have knowledge of the craft brewers' corporate ownership. This is a regrettable circumstance that I am not able to overcome. Fortunately, this will bias my results downward, making it more difficult to find support for my hypotheses. Thus, it is likely that the true effect size is larger than the coefficient estimates in my regressions. In my main regression, I use the following specification:

$$
Y_{i}=\alpha_{t}+\beta T_{i}+\gamma P_{i}+\theta\left(P_{i} \cdot T_{i}\right)+\epsilon_{i}
$$

Were $Y_{i}$ is one of three dependent variables: the evaluator's overall rating, perception of quality rating, or symbolic value rating. I describe these in detail below. $\alpha_{t}$ are year fixed effects, $\mathrm{T}$ is a dummy variable equal to one if the observation is from ratebeer.com. $\mathrm{P}$ is a dummy variable equal to one if the review occurred after the craft brewer was acquired. $\beta, \gamma$ and $\theta$ are estimated parameters and $\epsilon_{i}$ is a random error term. The unit of observation, $i$, is the review. Because I cannot precisely identify the date that the ratebeer.com updated the brewery name, I assume that treatment occurs on the first day any news source from LexisNexis reported on the acquisition, or the date of the official press release, whichever is sooner ${ }^{11}$. In other models I include acquisition fixed-effects, making the specification:

\footnotetext{
${ }^{11}$ If ratebeer.com is delayed in updating the website to reflect the acquisition, then this will bias my results downward.
} 


$$
Y_{i}=\alpha_{T}+\lambda_{j}+\beta T_{i}+\gamma P_{i}+\theta\left(P_{i} \cdot T_{i}\right)+\epsilon_{i}
$$

Where all variables are the same as equation 1 and $\lambda_{j}$ are product fixed effects. Standard errors are clustered at the acquisition level. In addition to the standard OLS assumptions, I make one further identifying assumption in this specification (known as the parallel trends assumption), which assumes that the pre-treatment trends of the treatment and control groups are equal. I explore the prudence of this assumption after describing the variable constructions.

\subsection{Dependent Variables}

I use product ratings data from ratebeer.com and beeradvocate.com to construct my dependent variables (See Table 1). Both websites require users to rate products on five criteria (See Figure 3). These criteria are common in beer judging competitions and tastings. Four of these criteria, which I refer to collectively as "perceptions of quality," relate to sensory product quality: aroma (or smell), appearance, taste, palate (or mouth-feel). Rather than equally weighting the component reviews, I standardize and rescale each "objective" dimension to match those used by beeradvocate.com ${ }^{12}$ (Alström 2014). The weights given are: taste (40\%), aroma (24\%), mouth-feel (10\%) and appearance $(6 \%)^{13}$. To test the robustness of my results, I later use an alternative specification that is not dependent on these weights.

The fifth ratings dimension is labeled "overall." The "overall" rating dimension has no objective criteria. It is simply a measure of how well the consumer "liked" the product. This includes all "objective" criteria, like taste, as well as any other value that the rater derives from consuming the product. Ratebeer.com describes this criteria as "Your overall impression of the beer" (Alström 2014). Finally, I rescale the ratings to a 100-point scale so that coefficients can be easily interpreted as percentage points. See Table 1 for descriptive statistics.

Using the above variables, I construct two dependent variables. Specifically, I construct a measure of perceived product quality and of symbolic value.

Perception of Quality. I develop a product quality measure to test hypothesis 1. The product quality variable captures perceptions of the physical object after experiencing the product. To construct this variable, I aggregate the weighted taste, aroma, appearance and palate measures to develop a composite score of audience perceptions of product quality (See Figure 4). Importantly, these four constituent variables capture all sensory perceptions except for hearing (which has a negligible effect on beer ratings), making them a near exhaustive measure of sensory perception

\footnotetext{
${ }^{12}$ Ratebeer.com does not publish the weightings used in their algorithm.

13 These sum up to $80 \%$. The remainder $20 \%$ will be what I refer to as 'symbolic value', which is the difference between the user's overall rating and the sum of all their other weighted ratings.
} 
Table 1 Summary Statistics: Comparison of Treatment and Control Group

\begin{tabular}{llccccc}
\hline \hline & & Overall & Taste & Aroma & Palate & Appearance \\
& Rating & Rating & Rating & Rating & Rating \\
\hline BeerAdvocate.com (Control) & Mean & 63.5 & 19.3 & 11.2 & 4.8 & 3.0 \\
& S.D. & 23.9 & 8.2 & 4.7 & 1.9 & 1.1 \\
& Min & 0 & 0 & 0 & 0 & 0 \\
& Max & 100 & 32 & 19.2 & 8 & 4.8 \\
\hline RateBeer.com (Treatment) & Mean & 58.1 & 17.4 & 9.8 & 3.7 & 2.4 \\
& S.D. & 31.8 & 9.4 & 5.8 & 2.2 & 1.3 \\
& Min & 0 & 0 & 0 & 0 & 0 \\
& Max & 100 & 32 & 19.2 & 8 & 4.8 \\
\hline Total & Mean & 60.2 & 18.1 & 10.4 & 4.1 & 2.7 \\
& S.D. & 29.1 & 9.0 & 5.5 & 2.2 & 1.3 \\
& Min & 0 & 0 & 0 & 0 & 0 \\
& Max & 100 & 32 & 19.2 & 8 & 4.8 \\
\hline \hline
\end{tabular}

\section{ratebeers Beeradvocate}

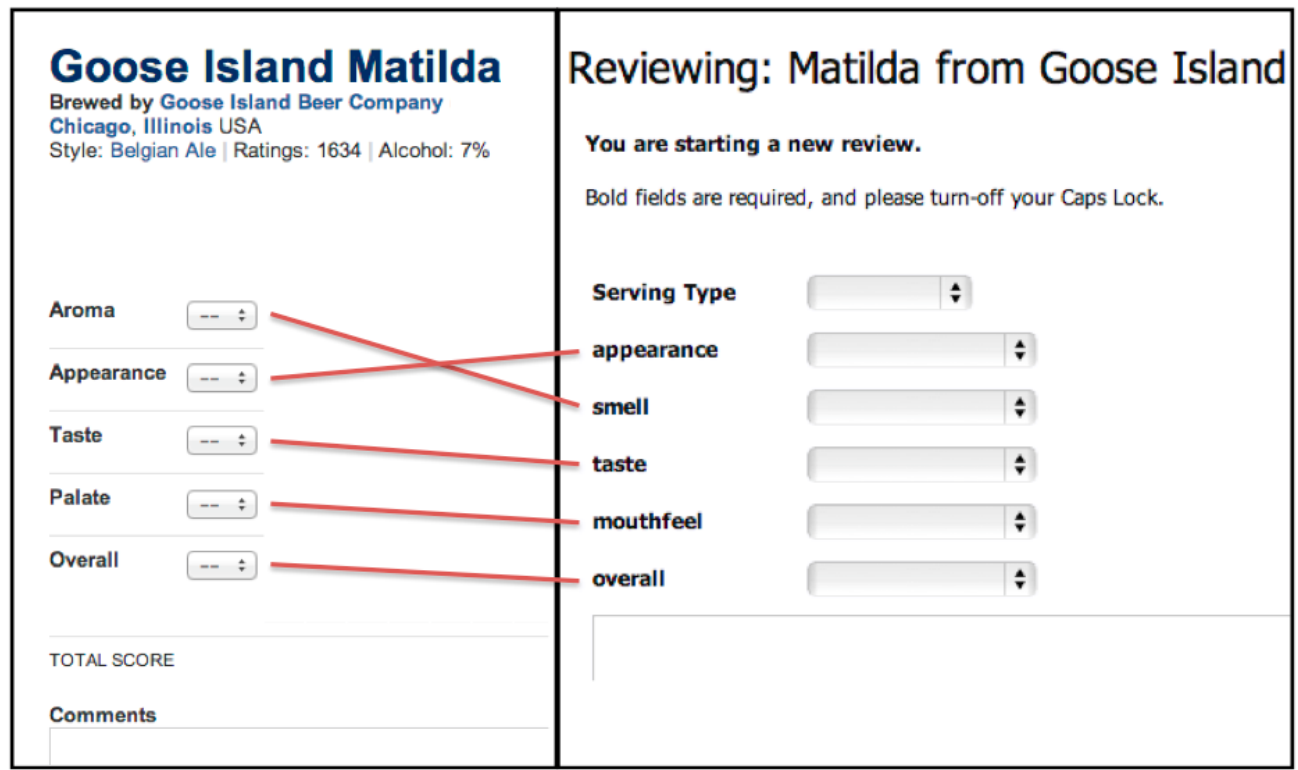

Figure 3 Comparison of treatment (ratebeer.com) and control (beeradvocate.com) ratings websites.

of the physical object. Furthermore, any "actual" product changes will be accounted for by the difference-in-difference design. Therefore, this variable construction, in conjunction with the empirical design described above, allows me to identify effects to perceived (sensory) product quality while holding actual product quality constant.

Symbolic Value. I develop a measure of symbolic value to test hypothesis 2. Following Bourdieu (1985), I conceptualize a good as having two parts: the physical object and the symbolic object. Perhaps an ideal measure would capture audiences ratings of "symbolic value "directly. Unfortu- 
nately, this measure is not available. Rather, to operationalize symbolic value I subtract a user's "perception of quality" rating from their "Overall Rating" (See Figure 4) ${ }^{14}$. This construction makes an important assumption that the difference between the overall rating and "perception of quality" rating can be attributed to "symbolic value" ${ }^{15}$. It is possible that this variable may contain residual quality evaluations that are not captured by the four "perception of quality" dimensions. For example, it may capture how well the reviewer enjoyed his environment, his drinking companions, or price. However, with the assumption that these factors are not systematically correlated with treatment (knowledge of a craft brewers inauthenticity) this will merely inflate the standard errors of the regressions, making it more difficult to find support for the hypothesis ${ }^{16}$.

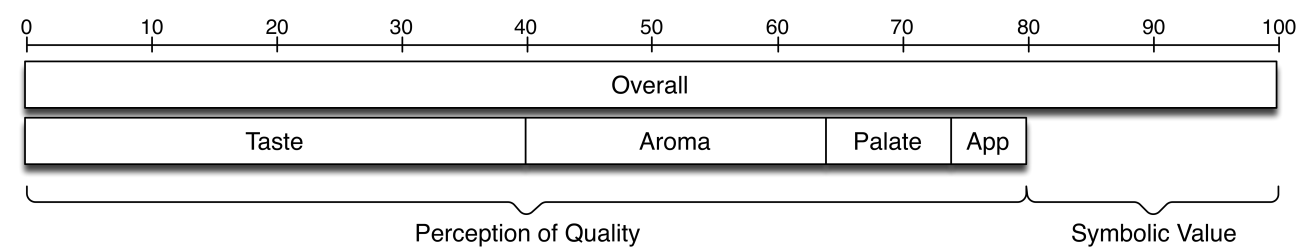

Figure 4 Dependent variable construction.

\subsection{Independent Variable: Corporate Ownership as Inauthenticity}

Organizational (In)Authenticity. Unfortunately, I am not able to directly observe audience perceptions of inauthenticity. Rather, I must assume that knowledge of a craft brewer's corporate ownership reduces audience perceptions of the 'craft' brewer's authenticity. I support this assumption in a variety of ways. First, I rely on previous studies of authenticity that have argued, and found evidence for, the connection between organizational form and perceptions of authenticity. Kovács et al. (2013) found that independent and family-owned restaurants were considered more authentic than chain-affiliated and corporately-owned restaurants. Further, Carroll and Swaminathan (2000) study the craft beer industry, specifically, and argue that "the identity problems of both mass production and contract brewers emanate from their organizational form and revolve around questions of... authenticity." 17

Popular media and industry insiders also suggest that corporate ownership of craft brewers is considered inauthentic by consumers. Dan Kenary, co-founder and CEO of Harpoon Brewery, said

\footnotetext{
${ }^{14}$ While more closely aligned with Bourdieu's (1985) construct of symbolic value, this dependent variable construction is sensitive the the wights given to each dimension of product quality. Therefore, I later use an alternative specification, which is not dependent on these weights, to estimate symbolic value.

15 To investigate the appropriateness of this assumption, I compared the symbolic ratings of corporate and craft brewers on ratebeer.com. Measures of symbolic value are about twice as high for craft brewers.

16 This is because the inclusion of them in the dependent variable will introduce noise.

${ }^{17}$ Contract brewer refers to small brewers who sell beer manufactured by corporate brewers.
} 
that there "certainly is a wonderful subset of consumers that really do care - they care about authenticity, they care about where their beer is brewed, who's brewing it, what the ethics are of the company" (Kaplan and Boyden 2015). Media outlets also suggest that audiences perceive corporate ownership of craft brewers as a betrayal of the craft movement. Lewis (2014, p. 196) explains that seeing "Goose Island sold to Anheuser-Busch was for many beer drinkers like watching their father pack up his bags and step out for cigarettes." He further argued that the acquisition "felt all the more like a betrayal because Anheuser-Busch had long served as the face of the enemy." John Laffler, a brewer at Goose Island, explained that, after being bought by AB-InBev, other craft brewers demonized the corporate ownership, saying "You guys are owned by the devil" (Schneider 2012). Ian Coutts, an author on the craft beer movement, remarked in an interview with Forbes (Wu 2015) that there is "a question of authenticity for the [corporate] brewers... It's like indie bands. You've got to be authentic."

The Brewers Association, a craft beer trade group, has defined craft brewery in a way that specifically excludes craft brewers who are owned by corporate brewers from the "craft" category. The Brewers Association says that a brewery is not considered craft if more than " 25 percent of the craft brewery is owned or controlled (or equivalent economic interest) by an alcoholic beverage industry member that is not itself a craft brewer" (Brewers Association 2015). Therefore, according to this definition, all of the brewers in my sample are considered authentic craft beer producers prior to acquisition and none of them are considered craft brewers after acquisition.

\subsection{Pre-treatment Trend Analysis}

To assess the reasonableness of the parallel trends assumption on which the difference-in-difference design depends, I drop all post-acquisition observations from my sample. I then regress the product's overall score on a dummy ("Treatment Group") indicating whether the review is in the treatment or control group, an ordinal variable ("Days from Treatment") indicating the number of days prior to treatment the review was submitted, and the interaction of these two variables. In models 1-2 of Table 2, I only include reviews submitted between zero and 180 days from acquisition. I expand the time frame to 365 days in models 3 and 4 . Models 2 and 4 include year and product fixed-effects. Across all specifications, the interaction term is small and insignificant, indicating that there are no significant pre-treatment trend differences between the two groups.

\subsection{Results}

I begin by establishing the effect of inauthenticity on overall product ratings by comparing the reviews of those made aware of a craft brewer's corporate ownership (treatment group) to those who were not (control group) before and after acquisition. In Table 3, I estimate the effect that knowledge of corporate ownership has on overall ratings. In the baseline model (Model 1), I show the 
Table 2 Pre-Treatment Trend Analysis

\begin{tabular}{lcccc}
\hline \hline & $(1)$ & $(2)$ & $(3)$ & $(4)$ \\
& Overall & Overall & Overall & Overall \\
& Rating & Rating & Rating & Rating \\
\hline RateBeer (Treatment Group) & $5.784^{* * *}$ & $8.988^{* * *}$ & 4.938 & $8.760^{* *}$ \\
& $(1.129)$ & $(0.730)$ & $(4.683)$ & $(1.215)$ \\
Days From Treatment & 0.0113 & 0.00442 & 0.00153 & $0.00557^{*}$ \\
& $(0.00740)$ & $(0.00542)$ & $(0.00372)$ & $(0.00149)$ \\
RateBeer X Days From Treatment & 0.00434 & 0.000445 & -0.00726 & -0.00306 \\
& $(0.0122)$ & $(0.00974)$ & $(0.00725)$ & $(0.00141)$ \\
Constant & $75.59^{* * *}$ & $74.00^{* * *}$ & $74.89^{* * *}$ & $74.38^{* * *}$ \\
& $(0.689)$ & $(1.147)$ & $(2.152)$ & $(0.618)$ \\
\hline Year Fixed-Effects & No & Yes & No & Yes \\
Product Fixed-Effects & No & Yes & No & Yes \\
Observations & 3642 & 3642 & 7206 & 7206 \\
$\mathrm{R}^{2}$ & 0.0230 & 0.0811 & 0.0306 & 0.0899 \\
Log-likelihood & -15734.1 & -14836.8 & -30917.8 & -29286.5 \\
\hline \hline
\end{tabular}

${ }^{*} p<0.05,{ }^{* *} p<0.01,{ }^{* * *} p<0.001$

Robust standard errors clustered at the acquisition level reported in parentheses.

main effect of being on RateBeer and in the post-acquisition period. The positive coefficient on the RateBeer dummy variable in Model 1 suggests the pre-acquisition ratings are higher on RateBeer than on BeerAdvocate. This difference will be accounted for by the difference-in-differences design. The insignificant negative coefficient for "Post Acquisition" in Model 1 suggests that, for users on BeerAdvocate (control group), being in the post treatment period has a negative effect. Although the coefficient is insignificant, there are two possible explanations for the negative coefficient. First, it may be that after acquisition there were real changes to the products (i.e. changes in recipe or distribution) that caused them to be rated lower. Second, it is possible that some people in BeerAdvocate (control group) were made aware of the acquisition through other channels (e.g. news reports or website forums). In other words, this may be evidence of treatment leakage. My estimates of the treatment effect in further models should, therefore, be conservatively interpreted as a lower bound.

I demonstrate the effect of organizational inauthenticity in Models 2 and 3 (Table 3). The significant coefficient on "RateBeer X Post Acquisition" in model 2 demonstrates an effect of organizational inauthenticity on overall product ratings. When compared to the users who were not made aware of a craft brewer's corporate ownership, users on RateBeer reduced their "overall" ratings significantly in the post-acquisition period $(\beta=-1.83)$. This represents about a three percent penalty to the average product in my treatment group. Model 3 adds product fixed-effects. As expected, the coefficient on the interaction term remains negative and significant $(\beta=-1.636)$. Because the dependent variable is the "overall rating," which includes evaluations of the product's 
Table 3 Effect of Inauthenticity on “Overall” Product Ratings

\begin{tabular}{lccc}
\hline \hline & $(1)$ & $(2)$ & $(3)$ \\
& Overall Rating & Overall Rating & Overall Rating \\
\hline Main Effects: & & & \\
$\quad$ RateBeer (Treatment Group) & $7.783^{* *}$ & $8.601^{* *}$ & $9.385^{* * *}$ \\
& $(1.047)$ & $(1.110)$ & $(1.045)$ \\
Post Acquisition & -2.375 & -1.423 & 0.934 \\
& $(1.439)$ & $(1.360)$ & $(0.547)$ \\
Treatment Effect: & & & \\
$\quad$ & & $-1.830^{* *}$ & $-1.636^{* * *}$ \\
$\quad$ RateBeer X Post Acquisition & Yes & $(0.241)$ & $(0.174)$ \\
& No & Yes & Yes \\
Year Fixed-Effects & 13398 & 13398 & 13398 \\
Product Fixed-Effects & 0.269 & 0.270 & 0.0801 \\
Observations & -55828.9 & -55823.4 & -54531.1 \\
$\mathrm{R}^{2}$ & \multicolumn{3}{c}{} \\
Log-likelihood & \multicolumn{3}{c}{} \\
\hline \hline${ }^{*} p<0.05,{ }^{* *} p<0.01,{ }^{* * *} p<0.001$ & & \\
Robust standard errors clustered at the acquisition level reported in parentheses. &
\end{tabular}

quality (taste, aroma, etc.) and its symbolic value, I am not able to distinguish the operative mechanism responsible for the ratings using this specification.

In Table 4, I test my hypotheses directly in order to distinguish between the effects that inauthenticity has on audience perceptions of quality from perceptions of symbolic value. Model 1 suggests that perceptions of quality are not significantly impacted by knowledge of a craft brewer's corporate ownership. The average treatment effect ("RateBeer X Post Acquisition") on audience perceptions of product quality is small, positive and insignificant $(\beta=0.0895)$. Each dimension of the dependent variable (taste, aroma, appearance and mouth-feel) is independently small and insignificant as well (results not reported). This result fails to support hypothesis 1 that perceptions of inauthenticity affect perceptions of product quality. This result, however, should not be interpreted as evidence that audiences do not use authenticity to make quality inferences. It is reasonable to assume that these ratings are submitted after users have consumed the product. Even though "malt beverages are inherently difficult to categorize and evaluate because of their subtle and ambiguous complexities" (Carroll and Swaminathan 2000, p. 730), experiencing them does provide concrete information about the product's quality. If it were possible to observe the expected quality ratings before consumption, it is possible that I might observe this same audience using authenticity to make quality inferences. Furthermore, it may be that the effect size of inauthenticity on perceptions of quality is sufficiently small that I lack the statistical power to identify the effect. Finally, it may be that corporate ownership has heterogeneous effects on different audience members. Some audience members may believe that corporate ownership has a positive effect on quality (for example, because corporations can make larger investments in technology) while 
Table 4 Effect of Inauthenticity on Perceived Quality and Symbolic Value

\begin{tabular}{lccc}
\hline \hline & $(1)$ & $(2)$ & $(3)$ \\
& Perceived Quality & Symbolic Value & Overall Rating \\
\hline Main Effects: & & & \\
RateBeer (Treatment Group) & $0.593^{*}$ & $8.792^{* * *}$ & $8.966^{* * *}$ \\
& $(0.168)$ & $(0.887)$ & $(0.711)$ \\
Post Acquisition & -0.0920 & $1.026^{*}$ & $0.959^{*}$ \\
& $(0.270)$ & $(0.334)$ & $(0.255)$ \\
Treatment Effect: & & & \\
RateBeer X Post Acquisition & 0.0895 & $-1.726^{* * *}$ & $-1.709^{* * *}$ \\
& $(0.138)$ & $(0.162)$ & $(0.164)$ \\
Controls: & & & \\
Taste Rating & & & $1.735^{* * *}$ \\
& & & $(0.0338)$ \\
Aroma Rating & & & $0.736^{* * *}$ \\
Appearance Rating & & & $(0.0178)$ \\
Palate Rating & & & $1.147^{* *}$ \\
& & & $(0.173)$ \\
Year Fixed-Effects & & & $1.989^{* * *}$ \\
Product Fixed-Effects & Yes & & $(0.228)$ \\
Observations & Yes & Yes & Yes \\
$\mathrm{R}^{2}{ }_{\text {Log-likelihood }}$ & 13398 & 13398 & 13398 \\
\hline${ }^{*} p<0.05,{ }^{* *} p<0.01,{ }^{* * *} p<0.001$ & 0.00301 & 0.124 & 0.571 \\
R & -45098.9 & -50284.7 & -49413.9 \\
\hline
\end{tabular}

Robust standard errors clustered at the acquisition level reported in parentheses.

others may believe corporate ownership has a negative effect. For these reasons, the failure to find support for hypothesis 1 should not be interpreted as evidence that inauthenticity does not affect audience perceptions of quality.

In model 2 (Table 4), I test the effect of authenticity on the symbolic value that consumers attribute to the product. The estimated effect on symbolic value in model 2 suggests that inauthentic ownership causes a significant decline in perceptions of symbolic value $(\beta=-1.726)$. In model 3 , I use a different specification to address concerns that my results are dependent on the parametric assumptions introduced by the construction of the "Symbolic Value" measure. In model 3, I use the overall rating as the dependent variable and statistically control for quality ratings (taste, aroma, etc.). This relaxes any assumptions about the relative weights of each of these variables and allows the regression to effectively determine appropriate weights. The results are very similar to those of model $2(\beta=-1.709)$, which suggests that my results are not dependent on the parametric assumptions introduced by my construction of the "symbolic value" variable ${ }^{18}$. Therefore, hypothesis 2 is

${ }^{18}$ In analysis not reported here, I run separate regressions for each acquisition (five in total) and confirm that each coefficient of the DD term (RateBeer X Post Acquisition) is negative. However, they are not all statistically significant due to limited statistical power. 
supported. These results suggest that consumers devalue inauthentic organizations (craft breweries owned by corporate breweries) because they perceive them has having lower symbolic value.

\subsection{Alternative Explanations and Limitations}

There are several limitations and alternative explanations that may be raised in response to the above empirical analysis. The first is that the specifications may not completely control for changes to the product quality, freshness, distribution, etc. Fortunately, the empirical design (difference-indifferences estimation) will account for any "actual" changes with the additional assumption that "actual" changes will impact both websites equally. While I am not able to test this assumption directly, there is little reason to believe that one audience would receive substantially different quality products at any given time.

Another objection may be that the two websites in the sample (RateBeer and BeerAdvocate) might be populated by different types of consumers. For example, one group may be more concerned with inauthenticity than the other. Although there is no evidence to suggest that they are systematically different, this is not problematic for the research design conditional on there being no changes to the sample compositions that coincide with treatment. Other time-invariant differences between the populations of the websites are accounted for by the diff-in-diff. For example, RateBeer users tend to give higher ratings, on average, than users of BeerAdvocate. These differences are absorbed by the main effect (RateBeer) and therefore are not reflected in the interaction term (RateBeer X Post Acquisition Period). However, if there are systematic changes to the composition of the reviewers on the website(s), this may bias my results. For example, perhaps RateBeer is attracting more experienced or discerning users over time and BeerAdvocate is not. This could explain the negative effect I observe to RateBeer rating in the post acquisition period. While I cannot definitively rule this out, such a change should also affect "perceptions of quality" ratings (taste, aroma, etc.) as well as "overall" ratings. Because I observe no statistically significant effect to "perceptions of quality" (Table 4, Model 1), this regression effectively acts as a placebo test.

Another criticism is that the results are not due to perceptions of inauthenticity, but are due to changing perceptions of some other (correlated) constructs like size ${ }^{19}$. To test this alternative explanation, I performed a placebo test that replicates the analysis in Table 4 except on a sample of acquisitions that are not considered acts of inauthenticity. I identified two mergers/acquisitions (M\&A) between brewers that were not considered inauthentic. The first was a merger between Anheuser-Busch and InBev in 2008. This merger was not considered inauthentic because AnheuserBusch and InBev were both large, corporate breweries prior to the merger. Therefore, audiences are

\footnotetext{
19 Thanks to several anonymous reviewers and the editors for identifying this alternative explanation and for recom-
} mending additional analysis to address this concern. 
Table 5 Placebo Test

\begin{tabular}{|c|c|c|c|}
\hline & $\begin{array}{c}(1) \\
\text { Perceived Quality }\end{array}$ & $\begin{array}{c}(2) \\
\text { Symbolic Value }\end{array}$ & $\begin{array}{c}\text { (3) } \\
\text { Overall Rating } \\
\end{array}$ \\
\hline \multicolumn{4}{|l|}{ Main Effects: } \\
\hline RateBeer (Treatment Group) & $\begin{array}{l}-2.745 \\
(0.666)\end{array}$ & $\begin{array}{l}-4.793 \\
(2.850)\end{array}$ & $\begin{array}{l}-3.422 \\
(2.573)\end{array}$ \\
\hline Post Acquisition & $\begin{array}{c}0.547^{*} \\
(0.0857)\end{array}$ & $\begin{array}{c}0.720 \\
(0.377)\end{array}$ & $\begin{array}{c}0.609 \\
(0.368)\end{array}$ \\
\hline \multicolumn{4}{|l|}{ Treatment Effect: } \\
\hline RateBeer X Post Acquisition & $\begin{array}{r}-0.0118 \\
(0.159)\end{array}$ & $\begin{array}{c}0.913 \\
(0.733)\end{array}$ & $\begin{array}{c}0.906 \\
(0.677)\end{array}$ \\
\hline \multicolumn{4}{|l|}{ Controls: } \\
\hline Taste Rating & & & $\begin{array}{l}2.024^{* *} \\
(0.0668)\end{array}$ \\
\hline Aroma Rating & & & $\begin{array}{c}0.710^{*} \\
(0.129)\end{array}$ \\
\hline Appearance Rating & & & $\begin{array}{c}0.703 \\
(0.192)\end{array}$ \\
\hline Palate Rating & & & $\begin{array}{l}2.065^{*} \\
(0.227)\end{array}$ \\
\hline Constant & $\begin{array}{c}28.88^{* * *} \\
(0.391)\end{array}$ & $\begin{array}{l}23.65^{* *} \\
(1.763)\end{array}$ & $\begin{array}{l}8.039^{*} \\
(1.295)\end{array}$ \\
\hline Year Fixed-Effects & Yes & Yes & Yes \\
\hline Product Fixed-Effects & Yes & Yes & Yes \\
\hline Observations & 17824 & 17824 & 17824 \\
\hline $\mathrm{R}^{2}$ & 0.0184 & 0.0223 & 0.615 \\
\hline Log-likelihood & -66413.0 & -73120.2 & -71184.6 \\
\hline
\end{tabular}

unlikely to interpret the merger as inauthentic. The second merger was between Duvel Moortgat and Brewery Ommegang. Both breweries were considered craft before and after the merger took place (the combined size of the two breweries was not large enough for them to be considered a noncraft brewer). Therefore, this merger is also not considered an act of inauthenticity. Fortunately, both M\&A events did affect the breweries names on RateBeer but not on BeerAdvocate. For example Brewery Ommegang was listed as "Brewery Ommegang (Duvel-Moortgat)" on RateBeer after the merger. Although there were only two such M\&A events during my period, the sample size of this placebo test is larger than that in the main analysis. Therefore, the placebo test offers sufficient statistical power to find a similar-sized effect if one exists. Table 5 reports the results of the placebo test. The coefficient on "RateBeer X Post Acquisition" is small and insignificant in all models. This provides some evidence that the effects demonstrated in the main analysis are not spurious, driven primarily by increases in size, or the result of a simultaneous treatment on RateBeer. Finally, I run a difference-in-difference-in-differences (triple differences) analysis which uses the placebo group and the original control group (same product ratings from BeerAdvocate) 
as two separate control groups. This analysis controls for any "actual" changes to product quality as well as any other unintended treatments that displaying the acquirer's name might cause (apart from perceptions of inauthenticity). Table 6 shows that, after controlling for these factors, the coefficients remain negative and statistically significant. Therefore, it is unlikely that factors not related to authenticity, like perceptions of increased size, are driving the main results.

Table 6 Difference-in-Difference-in-Differences Analysis.

\begin{tabular}{|c|c|c|}
\hline & $\begin{array}{c}\text { (1) } \\
\text { Overall Rating }\end{array}$ & $\begin{array}{c}(2) \\
\text { Overall Rating }\end{array}$ \\
\hline \multicolumn{3}{|l|}{ Main Effects: } \\
\hline RateBeer (Treatment Group) & $\begin{array}{l}-5.610 \\
(2.587)\end{array}$ & $\begin{array}{l}-3.702 \\
(2.233)\end{array}$ \\
\hline Post Acquisition & $\begin{array}{c}3.029^{* * *} \\
(0.409)\end{array}$ & $\begin{array}{l}1.179^{*} \\
(0.340)\end{array}$ \\
\hline RateBeer X Post Acquisition & $\begin{array}{c}0.919 \\
(0.680)\end{array}$ & $\begin{array}{c}0.836 \\
(0.610)\end{array}$ \\
\hline Post Acquisition X Inauthentic & $\begin{array}{r}-2.165^{* *} \\
(0.523)\end{array}$ & $\begin{array}{r}-0.0441 \\
(0.446)\end{array}$ \\
\hline RateBeer X Inauthentic & $\begin{array}{l}14.35^{* *} \\
(2.721)\end{array}$ & $\begin{array}{l}12.77^{* *} \\
(2.465)\end{array}$ \\
\hline \multicolumn{3}{|l|}{ Treatment Effect: } \\
\hline RateBeer X Post X Inauthentic (DDD) & $\begin{array}{c}-2.703^{* *} \\
(0.708)\end{array}$ & $\begin{array}{c}-2.506^{* *} \\
(0.653)\end{array}$ \\
\hline \multicolumn{3}{|l|}{ Controls: } \\
\hline Taste Rating & & $\begin{array}{c}1.957^{* * *} \\
(0.126)\end{array}$ \\
\hline Aroma Rating & & $\begin{array}{l}0.585^{* * *} \\
(0.0990)\end{array}$ \\
\hline Appearance Rating & & $\begin{array}{l}0.953^{* *} \\
(0.226)\end{array}$ \\
\hline Palate Rating & & $\begin{array}{c}2.011^{* * *} \\
(0.249)\end{array}$ \\
\hline Year Fixed-Effects & Yes & Yes \\
\hline Product Fixed-Effects & Yes & Yes \\
\hline Observations & 31222 & 31222 \\
\hline $\mathrm{R}^{2}$ & 0.0618 & 0.688 \\
\hline Log-likelihood & -125497.9 & -121872.6 \\
\hline
\end{tabular}

This study is also limited in it's ability to precisely measure symbolic value. The measure of symbolic value assumes that the difference between a user's overall rating and their rating of the sensory perception of the beer ('perception of quality') can be wholly attributed to symbolic value. Unfortunately, there is little I can do to test this assumption. It is possible that other factors are being captured by this measure. For example, consumers may give a beer a higher "overall" rating 
if they enjoyed the environment they consumed the product in. To overcome this weakness, I must assume that all other factors are uncorrelated with treatment. With this assumption, these other factors simply add additional noise to the "symbolic value" measure, which will only inflate the standard errors (making it harder to find a significant effect). In the case that this assumption does not hold, a more conservative interpretation of my results is that knowledge of a craft brewers corporate ownership decreases audience's overall experience of a product independently of their sensory experience of it.

\section{Discussion}

Organizational scholars are becoming increasingly aware that social forces affect audience evaluations in organizational and market contexts. These evaluations have implications for how resources are allocated between products, organizations, and markets. Authenticity, in particular, has been recognized as an important socially constructed criterion (Gilmore and Pine 2009, Kovács et al. 2013, Hahl and Zuckerman 2014, Beverland 2005, Carroll and Wheaton 2009). Despite the increased interest, demonstrations of authenticity's causal effect on audience evaluations remain scant. I provide the first causal evidence from the field of an inauthenticity discount. I demonstrate that when authentic organizations behave inauthentically, they are punished by audience members who are made aware of their inauthentic behavior. I further show that acts of inauthenticity affect symbolic value, but do not seem to significantly impact audience perceptions of quality.

These findings may have implications for the scholarship on the diversification discount, which focuses primarily on supply-side mechanisms, by identifying the 'inauthenticity discount' as a unique demand-side mechanism that may lead customers to devalue products from diversifying firms, especially those in cultural goods markets. These results may also be of interest to scholars of entrepreneurship. If small organizations are considered more authentic, then authenticity may be one of the few competitive advantages that entrepreneurs have over large incumbent firms.

These findings may also have important implications for organizational scholars. For example, Kovács and Sharkey (2014) demonstrate that broad audience reach comes with costs. They find that books suffer from decreased ratings after winning prestigious awards and offer two possible mechanisms. First, the demographics and tastes of the broader, post-award audience may be different. Second, they suggest that audiences may be "turned off" by perceived popularity or mass-appeal of a book after winning an award. My results may be related to the latter mechanism. Specifically, if audiences perceive an item to be more popular or have mass appeal, then certain segments (connoisseurs or "snobs") may see them as less authentic and therefore discount them.

There is still much work do be done to understand the role of authenticity in market exchange. For example, Ody-Brasier and Vermeulen (2014) suggest that businesses also have socially constructed 
value functions. This begs the question: Do firms also value authentic exchange partners or is authenticity an exclusively consumer-driven phenomenon? Further, while my results suggest that authenticity does not significantly affect perceptions of quality in my setting, this may not always be the case. Beer ratings come after the evaluator has consumed the product. The results may differ if I could observe pre-consumption quality expectations. This has important economic implications. For example, consumers who are made aware of an organization's inauthentic identity may no longer purchase products from that organization or may actively campaign against it.

Finally, the symbolic value that audiences place on authenticity may have implications for practitioners operating in cultural goods markets. Entrepreneurs may be encouraged that, while they may lack the technological and market competence of incumbents, they are penitentially seen as more authentic by virtue of their independence from corporate forces and the identity of their equity holders. In certain niches, like craft beer, authenticity may act as a considerable barrier to entry for larger organizations. Entrepreneurs should also be cautioned that appeals to authenticity in the early stages of the firm's life may constrain viable exit options later in their life. My findings may also inform managers of large firms who wish to enter more lucrative niches defined by authenticity. Managers should consider that by attempting to acquire authenticity, they might be damaging the very authenticity that made the target attractive in the first place.

\section{Acknowledgments}

I am grateful to Christine Beckman for her encouragement and for very insightful feedback on several drafts of this paper. I am also grateful to Rajshree Agarwal, Oliver Hahl, David Waguespack, Hyejun Kim, Seth Carnahan, Daniel Olson, Waverly Ding, Brent Goldfarb, Rachelle Sampson, and participants of the Strategy and Entrepreneurship Student Presentation Series at the University of Maryland, the Medici Summer School (2015), the Academy of Management Annual Meeting (2015), and the Strategic Management Society Annual Conference (2015) for helpful comments. I thank Julian McAuley for generously sharing data from beeradvocate.com and ratebeer.com. Finally, I thank three anonymous reviewers, the associate editor, and the department editor, Olav Sorenson, for comments that significantly improved the paper. All remaining errors are my own. 


\section{References}

Alström T (2014) How to Review a Beer. URL http://www.beeradvocate.com/community/threads/ how-to-review-a-beer. $241156 /$.

Angrist JD, Pischke JS (2008) Mostly Harmless Econometrics. An Empiricist's Companion (Princeton University Press).

Baugh B (1988) Authenticity Revisited. The Journal of Aesthetics and Art Criticism 46(4):477-487.

Beverland MB (2005) Crafting Brand Authenticity: The Case of Luxury Wines. Journal of Management Studies 42(5):1003-1029.

Bourdieu P (1985) The Market of Symbolic Goods. Poetics 14(1-2):13-44.

Brewers Association (2015) Craft Brewer Defined. URL https://www.brewersassociation.org/ statistics/craft-brewer-defined/.

Bulik BS (2009) What Your Taste in Beer Says About You . URL http://adage.com/article/news/ psychographics-taste-beer/140106/.

Carroll GR, Swaminathan A (2000) Why the Microbrewery Movement? Organizational Dynamics of Resource Partitioning in the US Brewing Industry. American Journal of Sociology 106(3):715-762.

Carroll GR, Wheaton DR (2009) The organizational construction of authenticity: An examination of contemporary food and dining in the U.S. Research in Organizational Behavior 29:255-282.

Esterl M, Mickle T (2014) Beer Giants Cultivate Their Crafty Side. URL http://www.wsj .com/articles/ beer-giants-cultivate-their-crafty-side-1419806627.

Fine GA (2003) Crafting Authenticity: The Validation of Identity in Self-Taught Art. Theory and Society $32(2): 153-180$.

Gardner BB, Levy SJ (1955) The product and the brand. Harvard Business Review (March-April):33-40.

Gilmore J, Pine J (2009) Using art to render authenticity in business . Arts Business 11-58.

Glazer A, Konrad KA (1996) A Signaling Explanation for Charity. The American Economic Review 86(4):1019-1028.

Gneezy U, Rustichini A (2000) Pay Enough or Don't Pay at All. Quarterly Journal of Economics 115(3):791810 .

Grazian D (2005) Blue Chicago: The Search for Authenticity in Urban Blues Clubs (University of Chicago Press).

Grubb EL, Grathwohl HL (1967) Consumer Self-Concept, Symbolism and Market Behavior: A Theoretical Approach. Journal of Marketing 31(4):22-27.

Hahl O (2015) Turning Back the Clock in Baseball: The Increased Prominence of Rewards and Demand for Authenticity . Working Paper 1-49. 
Hahl O, Zuckerman EW (2014) The Denigration of Heroes? How the Status Attainment Process Shapes Attributions of Considerateness and Authenticity. American Journal of Sociology 120(2):504-554.

Hahl O, Zuckerman EW, Kim M (2015) Why Authenticity is In Demand: Overcoming High-Status Denigration with Outsider Art. Working Paper 1-67.

Hirschman EC, Holbrook MB (1982) Hedonic Consumption: Emerging Concepts, Methods and Propositions. Journal of Marketing 46(3):92-101.

Kaplan J, Boyden C (2015) A Merger Won't Solve Big Beer's Craft

Problem. URL http://www.bloomberg.com/news/articles/2015-10-07/

ab-inbev-s-merger-plans-still-leave-big-beer-vulnerable-to-craft.

Kim H (2016) Identity Shock: The Cost of Mainstream Publicity among Avant-Garde Knitters. Working Paper.

Kovács B, Carroll GR, Lehman DW (2013) Authenticity and consumer value ratings: Empirical tests from the restaurant domain. Organization Science 25(2):458-478.

Kovács B, Sharkey AJ (2014) The Paradox of Publicity How Awards Can Negatively Affect the Evaluation of Quality. Administrative Science Quarterly 59(1):1-33.

Lehman DW, Kovács B, Carroll GR (2014) Conflicting Social Codes and Organizations: Hygiene and Authenticity in Consumer Evaluations of Restaurants. Management Science 60(10):2602-2617.

Leibenstein H (1950) Bandwagon, Snob, and Veblen Effects in the Theory of Consumers' Demand. The Quarterly Journal of Economics 64(2):183-207.

Leonard D (2012) The Plot to Destroy America's Beer. URL http://www.bloomberg.com/bw/articles/ 2012-10-25/the-plot-to-destroy-americas-beer.

Leonard D (2015) Can Craft Beer Survive AB InBev? URL http://www.bloomberg.com/news/features/ 2015-06-25/can-craft-beer-survive-ab-inbev-.

Leung MD, Sharkey AJ (2014) Out of Sight, Out of Mind? Evidence of Perceptual Factors in the MultipleCategory Discount. Organization Science 25(1):171-184.

Levy SJ (1959) Symbols for Sale. Harvard Business Review 37(July-August):117-119.

Lewis S (2014) We Make Beer: Inside the Spirit and Artistry of America's Craft Brewers (New York, NY: St. Martin's Press).

Malter D (2014) On the Causality and Cause of Returns to Organizational Status Evidence from the Grands Crus Classés of the Médoc. Administrative Science Quarterly 59(2):271-300.

Mason RS (1981) Conspicuous Consumption: A Study of Exceptional Consumer Behaviour (New York: St. Martin's Press).

McAuley J, Leskovec J, Jurafsky D (2012) Learning Attitudes and Attributes from Online Reviews. Working Paper 1-11. 
McKendrick DG, Hannan MT (2014) Oppositional Identities and Resource Partitioning: Distillery Ownership in Scotch Whisky, 1826-2009. Organization Science 25(4):1272-1286.

Negro G, Hannan MT, Rao H (2011) Category Reinterpretation and Defection: Modernism and Tradition in Italian Winemaking. Organization Science 22(6):1449-1463.

Negro G, Hannan MT, Rao H, De Leung M (2007) No Barrique, No Berlusconi: Collective Identity, Contention, and Authenticity in the Making of Barolo and Barbaresco Wines. Working Paper 1-49.

Negro G, Leung MD (2013) "Actual" and Perceptual Effects of Category Spanning. Organization Science $24(3): 684-696$.

Ody-Brasier A, Vermeulen F (2014) The Price You Pay Price-setting as a Response to Norm Violations in the Market for Champagne Grapes. Administrative Science Quarterly 59(1):109-144.

Peterson RA (1997) Creating Country Music: Fabricating Authenticity (Chicago, IL: University of Chicago Press).

Peterson RA (2005) In Search of Authenticity. Journal of Management Studies 42(5):1083-1098.

Phillips DJ, Turco CJ, Zuckerman EW (2013) Betrayal as Market Barrier: Identity-Based Limits to Diversification among High-Status Corporate Law Firms. American Journal of Sociology 118(4):1023-1054.

Pontikes E, Negro G, Rao H (2010) Stained Red A Study of Stigma by Association to Blacklisted Artists during the "Red Scare" in Hollywood, 1945 to 1960. American Sociological Review 75(3):456-478.

Pontikes EG (2012) Two Sides of the Same Coin How Ambiguous Classification Affects Multiple Audiences' Evaluations. Administrative Science Quarterly 57(1):81-118.

Rao H, Monin P, Durand R (2005) Border crossing: Bricolage and the erosion of categorical boundaries in French gastronomy. American Sociological Review 70(6):968-991.

Rosenberg M (1979) Conceiving the Self (New York, NY: Basic Books).

Rossman G, Schilke O (2014) Close, But No Cigar The Bimodal Rewards to Prize-Seeking. American Sociological Review 79(1):86-108.

Ruddick G (2015) Beer titans opt to merge as trend for smaller craft brews comes to a head. URL http://www.theguardian.com/business/2015/oct/17/ sabmiller-ab-inbev-megabrew-craft-beer-ale-pubs.

Schneider P (2012) The Honk Heard Round The World: Goose Island One Year After The Sale. URL http://chicagoist.com/2012/04/16/the_honk_heard_round_the_world_goos.php.

Schultz EJ (2013) A-B InBev Proves a Good Home for Goose Island as Big Brewer Helps Cult Craft Rise. URL http://adage.com/article/news/years-a-b-inbev-good-goose-island/245676/.

Sexton SE, Sexton AL (2014) Conspicuous conservation: The Prius halo and willingness to pay for environmental bona fides. Journal of Environmental Economics and Management 67(3):303-317. 
Simcoe TS, Waguespack DM (2011) Status, quality, and attention: What's in a (missing) name? Management Science 57(2):274-290.

Sirgy MJ (1982) Self-concept in consumer behavior: A critical review. Journal of Consumer Research 9(3):287-300.

Spence M (1973) Job Market Signaling. The Quarterly Journal of Economics 87(3):355-374.

Trilling L (1972) Sincerity and Authenticity (Cambridge, MA: Harvard University Press).

Veblen T (1899) The Theory of the Leisure Class (New York, NY: MacMillan).

Verhaal JC, Khessina OM (2015) Oppositional product names, organizational identities, and product appeal. Organization Science 26(5):1466-1484.

Wu L (2015) What the Do-It-Yourself Craft Beer Pod Machine May Mean to the Canadian Consumer. URL http://www.forbes.com/sites/lesliewu/2015/10/31/ what-the-do-it-yourself-craft-beer-pod-machine-may-mean-to-the-canadian-consumer/.

Zuckerman EW (2012) Construction, Concentration, and (Dis)Continuities in Social Valuations. Annual Review of Sociology 38(1):223-245.

Zuckerman EW, Kim TY (2003) The critical trade-off: identity assignment and box-office success in the feature film industry. Industrial and Corporate Change 12(1):27-67.

Zuckerman EW, Kim TY, Ukanwa K, von Rittmann J (2003) Robust Identities or Nonentities? Typecasting in the Feature-Film Labor Market. American Journal of Sociology 108(5):1018-1073. 